\title{
Risk of sympathectomy after anterior and lateral lumbar interbody fusion procedures
}

\author{
Lumir Hrabalek ${ }^{\mathrm{a}}$, Jan Sternbersky ${ }^{\mathrm{b}}$, Milan Adamus
}

\begin{abstract}
Aim. The aim of this study was to identify retrospectively, lumbar sympathectomy (SE) using thermography (TG) and to evaluate clinically, the severity of post-sympathectomy (post-SE) dysfunction after anterior and lateral lumbar interbody fusion procedures (ALIF, XLIF).

Methods. Twenty eight patients with suspected SE were referred for TG to both legs. They completed our questionnaire on severity of difficulties after SE. We evaluated the ability of physical examinations to reveal the SE in contrast to TG and compared the symptoms (warmer leg and inhibited leg sweating) of SE with questionnaire responses as subjective measure and TG as objective measure.

Results. SE was diagnosed in $0.5 \%$ after ALIF at L5/S1, in $15 \%$ after ALIF at Th12-L5 and in 4\% after XLIF at T12-L5. SE severely reduced the quality of life in two cases. The ability to distinguish differences in leg temperature by palpation after SE was found in $32 \%$. All physical examinations together were insufficient for reliably disclosing SE. Subjective symptoms of SE were often false positive and proven SE by TG was often a clinically false negative.

Conclusion. This is the first study to examine post-SE dysfunction objectivelya using TG after ALIF and XLIF, and the first to evaluate clinically, the severity of the post-SE syndrome. Before surgery we cannot foresee potentially poor SE results. For this reason, injury to the sympathetic chain during surgery must be avoided. The advantage of TG for identifying SE is its non-invasiveness and reliability.
\end{abstract}

Key words: lumbar spine, sympathectomy, thermography, interbody fusion

Received: May 16, 2013; Accepted with revision: November 6, 2013; Available online: November 21, 2013 http://dx.doi.org/10.5507/bp.2013.083

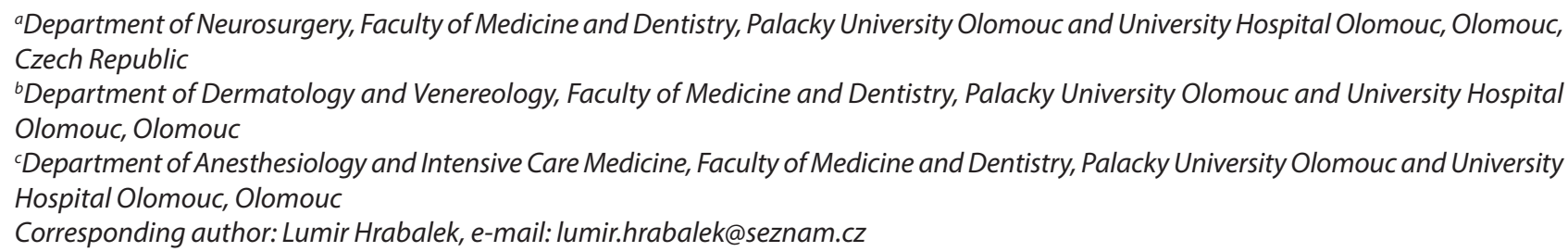

\section{INTRODUCTION}

Lumbar interbody fusion is a common surgical technique for the treatment of intervertebral disc diseases of degenerative or traumatic etiology ${ }^{1,2}$. During anterior or anterolateral minimally invasive approaches (ALIF - Anterior Lumbar Interbody Fusion) and lateral transpsoatic minimally invasive access (XLIF - Extreme Lateral Interbody Fusion) to the lumbar spine, it is sometimes necessary to sacrifice the lumbar sympathetic chain to obtain wider access to the discs ${ }^{3-5}$. The result of lumbar sympathectomy (SE) is post-sympathectomy (post-SE) dysfunction and it is usually characterized by increase in skin temperature, reduced perspiration and, sometimes, by dysestesias, discoloration and swelling of the lower limb on the side of surgery ${ }^{6-8}$. Patients commonly complain of a cold lower extremity on the side contralateral to the approach as the affected side is warmer due to loss of sympathetic vasoconstriction. However, some patients suffer from more severe difficulties, especially post-sympathectomy (post-SE) neuralgia ${ }^{9}$. The reported incidence of sympathetic dysfunction after ALIF is from $1 \%$ to $43 \%$ and after XLIF 4\% (ref. ${ }^{7,10-14}$ ).
The aim of this study was to identify retrospectively, lumbar SE using thermography (TG) and to evaluate clinically the severity of post-SE dysfunction.

\section{MATERIAL AND METHODS}

We reviewed all patients after minimally invasive techniques (MISS - Minimally Invasive Spine Surgery) of the anterior and lateral intervertebral disc surgery at levels T12-S1, treated at the Department of Neurosurgery from January 1996 to June 2012. Excluded were patients with CRPS (complex regional pain syndrome). The ALIF group after anterior approach at level L5/S1 consisted of 210 patients (129 women and 81 men), mean age 45 years. The ALIF group after anterolateral approach at levels T12-L5 consisted of 120 patients (53 women and 67 men), mean age 44 years and the XLIF group after lateral access at the same levels consisted of 101 patients ( 57 women and 44 men), mean age 51 years. 


\section{Surgical steps}

All types of surgery were performed retroperitoneally under balanced general anesthesia and adequate neuromuscular block for good surgical access; intravenous prophylactic antibiotics and low molecular weight heparin (LMWH) were obligatory.

\section{ALIF L5/S1}

A 6-8 $\mathrm{cm}$ skin incision (placed transverse in female or longitudinal in male) was made in the midline of the abdomen centered over L5/S1 which is usually the transition zone between the lower and middle third of the umbilical-symphyseal distance. The sheath of the right anterior rectus muscle was divided longitudinally along the direction of its fibers, the lateral part of the muscle was retracted laterally and the transversalis fascia divided as required. The peritoneum and its contents were then retracted medially by blunt dissection in the retroperitoneal space to expose the right iliopsoas muscle. The bifurcation of the right common iliac vessels and right ureter were identified. The ureter was swept medially with the peritoneum. The prevertebral retroperitoneal adipose tissue was exposed along the medial border of the right common iliac artery and carefully retracted to the left side including the superior hypogastric plexus, avoiding damage to the plexus. The left common iliac vein was identified and gently retracted to the left side. The retractor blades (Synframe, Synthes, USA) were then inserted underneath and between the common iliac vessels in order to expose the anterior intervertebral circumference, sympathetic chains from both sides were located laterally. Discectomy between and avoidance of sympathetic chains was achieved and titanium or PEEK (poly-ether-ether-keton) spacers were implanted. The retractor was removed, the fascia of rectus muscle, subcutaneous tissue and skin were sutured.

\section{ALIF T12-L5}

The patients were placed in a right lateral decubitus position. Anterolaterally and obliquely from the left side a 5-7 cm skin incision was made. The retroperitoneal space was reached by a blunt, muscle splitting approach. The anterolateral attachments of the psoas muscle were incised, sharply dissected and retracted laterally. The branches of the sympathetic chain were identified. The disc space level was then confirmed under fluoroscopic control. The retractor blades (Synframe, Synthes, USA) were then inserted anteriorly to retract retroperitoneum and great vessels (especially left iliac common vein) and posteriorly to retract psoas muscle in order to expose the anterolateral intervertebral circumference. Starting from the midline of the anterior longitudinal ligament, the annulus fibrosus was incised in its anterolateral circumference. The sympathetic chain was separated and retracted anteriorly or posteriorly. The disc was emptied and titanium or PEEK cages were inserted to the intervertebral space. The retractor was removed and the muscle layers, subcutaneous tissue and skin were sutured.

\section{XLIF T12-L5}

The patients were placed in a right lateral decubitus position. The skin was incised to a length $5-7 \mathrm{~cm}$ laterally and obliquely from the left side. The abdominal musculature was divided with blunt dissection by carefully splitting each muscle layer. After accessing the retroperitoneal space, the peritoneum was gently swept anteriorly and the dissection was carried bluntly down to the psoas muscle. The muscle fibers of the psoas were separated gently at the level of the disc under visual control to avoid injury of the genitofemoral nerve, nerve roots and sympathetic chain. The psoas muscle was divided into the anterior and posterior part. The surgeon inserted a K- wire between the anterior and middle third of the intervertebral disc space, then dilators and special retractor (Oracle, Synthes, USA). A tubular retractor was fixed to the table. Then the surgeon traced the course of the lumbar nerve roots with a stimulation electrode using triggered electromyography (tEMG) for intraoperative neuromonitoring (IOM). The sympathetic chain remained anterior to the retractor, out of the operating field and was not separated. Discectomy, endplate preparation, then interbody distraction and PEEK implant placement (Oracle, Synthes, USA) were performed. The incision was closed using the standard technique.

\section{Follow-up}

All surgical intra-operative and post-operative complications directly related to the spinal surgery were prospectively recorded. The neurosurgeon examined the patients and radiographs were obtained at follow-up examinations at 1 and 6 weeks, 6, 12 and 24 months.

We asked all the patients about symptoms of lumbar $\mathrm{SE}$, as warmer leg and inhibited leg sweating Physical examination of lower extremities was done to reveal signs of SE. Visual examination included evaluation of the skin color, trophic changes and swelling of the leg. Palpation (skin touching) of both legs was performed for evaluation of our ability to distinguish a difference in temperature of the legs without instruments.

The minimum follow-up required for inclusion to the study was 6 months after surgery. Other complications were not included in this study.

We referred for bilateral TG, as a sensitive test of SE, all patients with a description of partial or difficulties, despite the fact that SE was not described in the records. These comprised the study group. Patients with other complications such as an inflammatory focus of the legs, which can increase temperature in the thermogram, were excluded.

The standard examination with the thermal camera (FLIR thermal imaging camera type B-360 manufactured by an international company FLIR systems inc.) took place at a distance of one meter with an ambient temperature in the range of $23-25^{\circ} \mathrm{C}$. The camera was in a rectangle position to the examined part of human body. A thermal imaging camera can distinguish the temperature of an object with an accuracy of one tenth of a degree Celsius. The examination of each patient was 


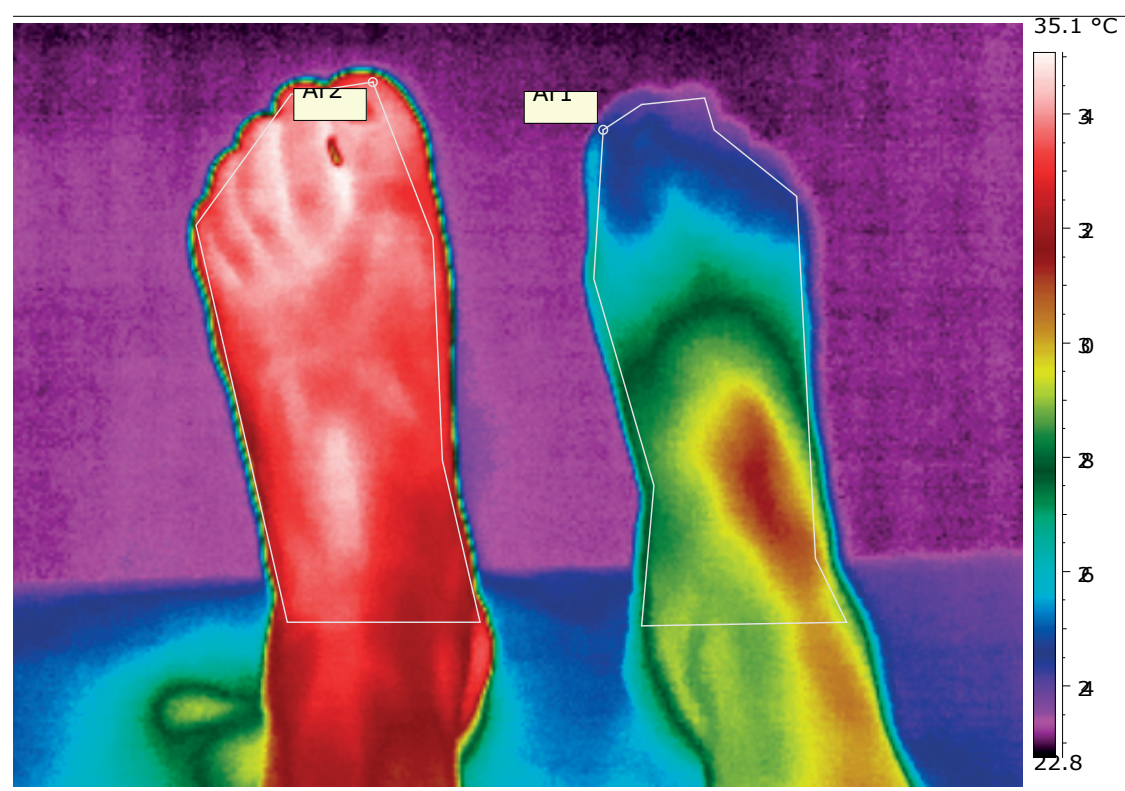

Fig. 1. Thermogram of the feet after ALIF L4/5, mean difference in temperature $5.8^{\circ} \mathrm{C}$. Female, 52 years old.

preceded by acclimatization for $30 \mathrm{~min}$, which took place in the consultation room. During this time, the patient was naked from the waist down, except for underwear. The first image taken was a synoptic image, capturing both lower limbs as a whole. Then, four other regional images focused on thighs, calves, feet and soles were taken. The images, called thermograms, were digitally processed, then evaluated using the thermographic software provided by the manufacturer (Fig. 1). This software provides evaluation of measured temperature via spots or through an areas of various shapes - so called region of interest (ROI). Higher value of notice and especially repeatability have measurements using ROIs, because in selected ROI the software can assess minimal, maximal and mean value of the temperature in this area. So for our measurment we used ROIs localised in regions mentioned above. In our whole examination we tried to observe the Glamorgan Protocol, where is exactly mentioned in what circumstances to measure certain parts of human body ${ }^{15}$. Thermograms of thighs and calves were measured with patient lying on straight pad on his back with his joints in maximal extension and feet in parallel position. We've chosen lying position instead of standing position, because many of our patients suffered from big backache or joint pain, which limitated them from still standing, even parallel position of legs was sometimes hard to fulfil. The feet and soles were also measured in lying patient. The feet were measured in parallel position with big toes pointing forward. The soles were measured in maximal flection in ankle joints and again in parallel position. All thermograms were captured with its examinated areas localised in the middle of the obtained picture with the same distances from the side edges of the picture ${ }^{16,17}$.

For TG we indicated altogether 28 patients ( 16 female and 12 male, mean age 53 years with range $36-74$ years)
- as a study group. Two patients were after ALIF L5/S1 (2/210 in group ALIF L5/S1), 18 patients after ALIF at level L4/5, two patients after ALIF at level L3/4 and two patients at level L2/3 (22/120 in group ALIF T12-L5). Three patients were after XLIF at level L4/5 and one at level L5/6 (4/88 in group XLIF T12-L5).

To the TG were also referred five patients (one female and four male) with mean age of 59 years (range 52-67 years) after lumbar disc herniation surgery from posterior approach, as a control group. In this control group without $\mathrm{SE}$, the temperature difference between the legs (all parts) according to TG was $0-0.9{ }^{\circ} \mathrm{C}$. For this reason, we decided to evaluate as a positive finding of SE in the study group a higher temperature in one or more parts of the leg on the side of surgery compared to the contralateral leg by $1.0{ }^{\circ} \mathrm{C}$ or more.

The patients of the study group were informed about the possibility of post-SE dysfunction (defined as warmer leg and/or inhibition of sweating of the leg) and they filled in our short questionnaire: severity of difficulties after sympathectomy, Grade 0-2. Patients had to choose one of three grades of difficulty (Table 1).

We evaluated the ability of the physical examinations to reveal SE in contrast to TG, as a yes or no.

The findings of TG (as an objective method) we compared with symptoms of SE and the results of the questionnaire for evaluation of severity of difficulty after sympathectomy (as subjective methods). We evaluated the consensus between objective versus subjective methods, as a yes or no.

In Table 2 are shown: the list of patients (divided into the study and control group), age, gender, level and type of surgery, symptoms of SE (warmer leg, inhibition of sweating of leg) and signs of SE (skin color, trophic changes, swelling of leg). 
Table 1. Severity of difficulties after sympathectomy, Grade 0-2.

\begin{tabular}{ll}
\hline & \multicolumn{1}{c}{ Questionnaire for patient } \\
\hline Grade 0: & I have no sense of post-SE dysfunction. \\
Grade 1: & $\begin{array}{l}\text { I have sense of post-SE dysfunction, but it is no } \\
\text { problem for quality of my life. }\end{array}$ \\
Grade 2: & $\begin{array}{l}\text { I have sense of post-SE dysfunction, and it is a } \\
\text { problem for quality of my life. }\end{array}$ \\
\hline
\end{tabular}

\section{RESULTS}

Table 3 shows the patient details (divided into study group and controls), evaluation of severity of difficulties after SE (Grade 0-2), time of TG after surgery, temperature in four parts of the legs (thigh, calf, foot, sole) according to TG, positivity of SE, ability to distinguish a difference in temperature of legs using palpation, consensus between TG and all physical examinations, consensus between objective method and subjective methods of postSE dysfunction.

In the study group, according to the scale "Severity of difficulties after SE" Grade 0 was reported by 18 patients, Grade 1 by eight patients, and Grade 2 by two patients. Eight patients reported onset of post-SE dysfunction over one week after surgery ( six with Grade 1, and two with Grade 2) and two patients over two months after surgery (both Grade 1).

TG was done on an average of 53 months (6 - 136 months) after surgery in the study group. According to patients suffering from post-SE dysfunction, their symptoms from the beginning to the time of TG remained unchanged.

Positive TG (a difference of $1.0{ }^{\circ} \mathrm{C}$ and more) as a proof of SE was found in 23 patients: 1/210 (0.5\%) in ALIF L5/S1, 18/120 (15\%) in ALIF T12-L5, 4/101 (4\%) in XLIF T12-L5.

In the study group, the ability to distinguish a difference in temperature of the legs using the sense of palpation after SE was found in 9 cases $(32 \%)$, while the difference between the legs was in interval of $1.0-8.1{ }^{\circ} \mathrm{C}$. In contrast, palpation was unable to distinguish the temperature of the legs after SE in 19 patients. The difference between the legs was in the interval of $0-4.3{ }^{\circ} \mathrm{C}$.

The consensus between TG and all physical examinations together (visual evaluation and palpation) was found in 12 cases of the study group. In 16 cases it was not possible to reveal post-SE dysfunction using the senses, without instruments.

The consensus between objective (TG) and subjective methods (symptoms of SE and results of questionnaire for evaluation of Severity of post-SE dysfunction) was found in 17 cases in the study group. In 11 cases there was no consensus (TG had positive results, but patients had no subjective difficulties in 8 cases, or on the contrary, patients had subjective difficulties without positive TG findings in 3 cases).

\section{DISCUSSION}

This is the first study, to our knowledge, that has examined post-SE dysfunction objectively, using thermography after anterior or lateral interbody fusion procedures, and the first study to evaluate clinically the severity of the post-SE syndrome. A similar study with evaluation of clinical outcome (Scoliosis Research Society SRS-22 patient questionnaire) of SE after scoliosis surgery with discectomies but without interbody fusion was reported by Schulte et al. They proposed that SE was detectable as an increase in temperature, reduced perspiration and reduced SSRs (sympathetic skin response) ( ref. $^{8}$ ). On the basis of the available literature, it can be accepted that temperature differences from the mean temperature of homologous control regions, i.e. between two opposing lower limbs, can be regarded as pathological if greater than $1{ }^{\circ} \mathrm{C}\left(\right.$ ref. $\left.^{8,18}\right)$.

Lumbar SE is indicated, as the method of choice, in cases of hyperhidrosis, CRPS and peripheral artery disease of the legs. According to the literature, neuropathic complications occur 3 times more often if the treatment was for neuropathic pain and not hyperhidrosis ${ }^{19}$. CRPS is a chronic systemic disease characterized by severe pain, swelling, and changes in the skin. Type II, formerly known as causalgia, is evidence of obvious nerve damage $^{20}$. Mizuno et al. concluded, that the sympathetic nervous system plays an important role in the generation of radicular pain and even low back pain. This may be a plausible explanation for the clinical effectiveness of sympathetic nerve block in cases of causalgia (CRPS) (ref. ${ }^{21}$ ). Rieger and Pedevilla performed bilateral lumbar SE at level L3/4 and pedal sweat secretion was completely suspended postoperatively. After a 3- to 8-months followup period, the anhidrosis persisted in all cases. None of the patients experienced sexual dysfunction ${ }^{22}$.

In all these indications, often described was postSE neuralgia. Post-SE neuralgia is defined according to Kramis et al. as a complex neuropathic and central deafferentation/reafferentation syndrome dependent on: (a) the transection, during sympathectomy, of paraspinal somatic and visceral afferent axons within the sympathetic trunk; (b) the subsequent cell death of many of the axotomized afferent neurons, resulting in central deafferentation; and (c) the persistent sensitization of spinal nociceptive neurons by painful conditions present prior to sympathectomy. Viscerosomatic convergence, collateral sprouting of afferents, and mechanisms associated with sympathetically maintained pain are all proposed to be important to the development of the syndrome ${ }^{9}$. Lumbar post-SE neuralgia is described as a severe, deep aching or burning pain, usually worse at night, referred to the lumbosacral area and proximal part of the limb only, to the groin and anterior thigh. This neuralgiform pain after lumbar SE is a known phenomenon reported in the literature with a frequency of $2 \%$ to $100 \%$ (ref. $^{23,24}$ ). Rieger and Pedevilla reported that $50 \%$ of patients experienced neuralgiform pain 3 to 10 days after bilateral operation for plantar hyperhidrosis. The affected patients were only men and the pain was localized in the back- 
Table 2. List of patients; symptoms and signs of sympathectomy.

\begin{tabular}{|c|c|c|c|c|c|c|c|c|}
\hline List & Age & Gen & Type, level & Warmer & Sw. loss & Color & Trophic ch. & Swelling \\
\hline \multicolumn{9}{|c|}{ Study gr. } \\
\hline 1 & 56 & M & ALIF L5/S1 & no & no & no & no & no \\
\hline 2 & 50 & M & ALIF L5/S1 & yes & yes & no & no & no \\
\hline 3 & 55 & $\mathrm{~F}$ & ALIF L4/5 & yes & no & no & dry & no \\
\hline 4 & 51 & M & ALIF L4/5 & yes & yes & no & no & no \\
\hline 5 & 55 & M & ALIF L4/5 & no & yes & no & no & no \\
\hline 6 & 56 & M & ALIF L4/5 & no & no & no & no & no \\
\hline 7 & 66 & M & ALIF L4/5 & yes & no & no & no & no \\
\hline 8 & 41 & $\mathrm{~F}$ & ALIF L4/5 & yes & no & no & no & no \\
\hline 9 & 51 & $\mathrm{~F}$ & ALIF L4/5 & yes & yes & red & dry & no \\
\hline 10 & 36 & M & ALIF L4/5 & no & no & no & no & no \\
\hline 11 & 59 & $\mathrm{~F}$ & ALIF L4/5 & yes & no & no & no & no \\
\hline 12 & 44 & $\mathrm{~F}$ & ALIF L4/5 & yes & yes & no & no & no \\
\hline 13 & 56 & M & ALIF L4/5 & yes & no & no & no & no \\
\hline 14 & 63 & M & ALIF L4/5 & no & no & no & no & no \\
\hline 15 & 57 & $\mathrm{~F}$ & ALIF L4/5 & no & no & no & no & no \\
\hline 16 & 67 & $\mathrm{~F}$ & ALIF L4/5 & yes & no & no & dry & no \\
\hline 17 & 52 & $\mathrm{~F}$ & ALIF L4/5 & yes & yes & no & no & no \\
\hline 18 & 37 & M & ALIF L4/5 & contralat & no & no & no & no \\
\hline 19 & 55 & $\mathrm{~F}$ & ALIF L4/5 & no & no & no & no & no \\
\hline 20 & 65 & $\mathrm{~F}$ & ALIF L4/5 & contralat & contralat & no & no & no \\
\hline 21 & 74 & F & ALIF L3/4 & no & no & no & no & no \\
\hline 22 & 57 & $\mathrm{~F}$ & ALIF L3/4 & yes & no & no & no & no \\
\hline 23 & 46 & M & ALIF L2/3 & no & yes & no & no & no \\
\hline 24 & 46 & M & ALIF L2/3 & no & no & red & dry, ulcer & yes \\
\hline 25 & 43 & $\mathrm{~F}$ & XLIF L5/6 & yes & no & no & no & no \\
\hline 26 & 51 & $\mathrm{~F}$ & XLIF L4/5 & yes & yes & no & no & no \\
\hline 27 & 56 & $\mathrm{~F}$ & XLIF L4/5 & yes & yes & no & no & no \\
\hline 28 & 42 & $\mathrm{~F}$ & XLIF L4/5 & no & no & no & no & no \\
\hline \multicolumn{9}{|c|}{ Control gr. } \\
\hline 1 & 59 & M & he L5/S1 dx. & no & no & no & no & no \\
\hline 2 & 54 & M & he $\mathrm{L} 5 / \mathrm{S} 1 \mathrm{sin}$. & no & no & no & no & no \\
\hline 3 & 52 & $\mathrm{~F}$ & he $\mathrm{L} 5 / \mathrm{S} 1 \mathrm{sin}$. & no & no & no & no & no \\
\hline 4 & 63 & M & he $\mathrm{L} 4 / 5 \mathrm{dx}$. & no & no & no & no & no \\
\hline 5 & 67 & M & he $\mathrm{L} 4 / 5 \mathrm{dx}$. & no & no & no & no & no \\
\hline
\end{tabular}

Age: age at time of TG (years)

Gen: gender - female (F), male (M)

Type, level: type of surgery (ALIF or XLIF), level of the spine,

Warmer: warmer leg compare to the contralateral side (yes/no)

Sw. loss: inhibition of sweating of the leg (yes/ no)

Color: skin color changes of the leg (yes -red/no)

Trophic ch: skin trophic changes of the leg (yes -dry/no)

Swelling: swelling of the leg (yes/no).

contralat: the findings are on the contralateral leg then expected 
Table 3. Results of clinical examinations and thermography.

\begin{tabular}{|c|c|c|c|c|c|c|c|}
\hline List & Severity & Time & Temp of T, C, F, S & SE & Palpation & Con TG-PE & Con Obj-Subj \\
\hline \multicolumn{8}{|c|}{ Study gr. } \\
\hline 1 & 0 & 9 & $(-) 0.10 .40 .00 .3$ & no & no & yes & yes \\
\hline 2 & 1 & 12 & (-)0.2 0.20 .83 .0 & yes & no & no & yes \\
\hline 3 & 1 & 130 & 0.30 .51 .11 .6 & yes & yes, foot & yes & yes \\
\hline 4 & 0 & 20 & $(-) 0.7-0.52 .02 .9$ & yes & yes, foot & yes & yes \\
\hline 5 & 1 & 23 & $(-) 0.10 .53 .14 .3$ & yes & no & no & yes \\
\hline 6 & 0 & 23 & (-)0.4 0.21 .32 .4 & yes & no & no & no \\
\hline 7 & 0 & 26 & $(-) 0.20 .01 .42 .1$ & yes & no & no & yes \\
\hline 8 & 0 & 62 & $(-) 0.10 .62 .23 .7$ & yes & no & no & yes \\
\hline 9 & 1 & 31 & 0.10 .13 .14 .7 & yes & yes, foot & yes & yes \\
\hline 10 & 0 & 62 & 0.40 .43 .33 .0 & yes & no & no & no \\
\hline 11 & 0 & 48 & $(-) 0.60 .22 .02 .1$ & yes & no & no & yes \\
\hline 12 & 2 & 48 & $(-) 0.30 .42 .43 .6$ & yes & no & yes & yes \\
\hline 13 & 0 & 78 & $0.00 .4-0.1-0.5$ & no & yes, foot & no & no \\
\hline 14 & 0 & 76 & $0.0-0.1 \quad 1.33 .7$ & yes & no & no & no \\
\hline 15 & 0 & 136 & (-)0.2 -0.21 .01 .1 & yes & no & no & no \\
\hline 16 & 1 & 36 & 0.00 .74 .34 .8 & yes & yes, foot & yes & yes \\
\hline 17 & 2 & 22 & 0.30 .75 .88 .1 & yes & yes, foot & yes & yes \\
\hline 18 & 0 & 46 & $(-) 0.10 .20 .40 .9$ & no & contralat & no & no \\
\hline 19 & 0 & 60 & (-)0.1 $-0.1-1.11 .2$ & yes & no & no & no \\
\hline 20 & 1 & 40 & $(-) 0.1-0.6-0.50 .2$ & no & contralat & yes & yes \\
\hline 21 & 0 & 124 & 0.10 .71 .81 .6 & yes & no & no & no \\
\hline 22 & 0 & 101 & $\begin{array}{llll}0.8 & 1.0 & 0.3 & 0.4\end{array}$ & yes & yes, calf & yes & yes \\
\hline 23 & 1 & 124 & $\begin{array}{llll}0.6 & 0.7 & 0.4 & 0.5\end{array}$ & no & no & yes & no \\
\hline 24 & 0 & 60 & 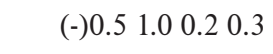 & yes & no & yes & no \\
\hline 25 & 0 & 9 & $(-) 0.20 .00 .91 .0$ & yes & no & no & yes \\
\hline 26 & 1 & 6 & (-)0.4 0.52 .93 .3 & yes & yes, foot & yes & yes \\
\hline 27 & 0 & 53 & $0.2 \quad 0.41 .51 .3$ & yes & no & no & yes \\
\hline 28 & 0 & 20 & $(-) 0.40 .40 .91 .9$ & yes & no & no & no \\
\hline \multicolumn{8}{|c|}{ Control gr. } \\
\hline 1 & 0 & 0 & $(-) 0.40 .00 .4-0.4$ & no & no & yes & yes \\
\hline 2 & 0 & 0 & (-)0.1 $0.3-0.6-0.2$ & no & no & yes & yes \\
\hline 3 & 0 & 0 & $(-) 0.50 .50 .00 .5$ & no & no & yes & yes \\
\hline 4 & 0 & 0 & (-)0.1 $0.5-0.20 .3$ & no & no & yes & yes \\
\hline 5 & 0 & 0 & $\begin{array}{llll}0.3 & 0.3 & 0.8 & 0.9\end{array}$ & no & no & yes & yes \\
\hline
\end{tabular}

Severity: Severity of difficulties after SE (Grade $0-2$ )

Time: time of TG after surgery (months)

Temperature of thigh, calf, foot, sole:

in the study group: difference in the mean temperature of four parts of the leg comparing to the contralateral side (Celsius degree) - positive (warmer leg on the side of surgery), negative (warmer was the contralateral leg);

in the control group: difference in the mean temperature of four parts of right leg compare (minus) to left leg (Celsius degree),

SE: the positivity of SE with difference in temperature $\left(1^{\circ} \mathrm{C}\right.$ or more) according to TG between legs (yes/no),

Palpation: warmer leg compare to the contralateral side using palpation (yes/no),

Con TG-PE: the consensus between TG and all physical examinations (yes/ no),

Con O-S: the consensus between objective (TG) and subjective symptoms of post-SE dysfunction (yes/no), contralat: the findings are on the contralateral leg than expected. 
side, groin, thighs, or calves with no neurologic deficits ${ }^{22}$. Later, Rieger described a group of 18 patients (14\%) who experienced transient neuralgiform pain that usually persisted only a few weeks and in individual cases for several months ${ }^{25}$. Mockus et al. performed SE for CRPS and postSE neuralgia occurred in close to $40 \%$, lasted a little over a month on the average, but did not persist beyond ten weeks ${ }^{26}$. Lacroix et al. described two cases (5\%) of post-SE neuralgia in a group of patients with reflex sympathetic dystrophy and arterial insufficiency ${ }^{27}$.

CRPS and post-SE neuralgia; this appears to be two similar disease states that have different physiological bases. One is termed "sympathetically maintained pain". In these patients blockade of autonomic function relieves the CRPS. A clinically similar syndrome in which the autonomic nervous system is not involved is called "sympathetically independent pain". The induction of adrenergic excitability in CPMs (C-fiber polymodal) nociceptors by $\mathrm{SE}$ is suggested to be a counterpart to post-SE neuralgia in human beings and a possible part of the mechanism leading to sympathetically related pain states ${ }^{28}$. The danger of injury to the superior hypogastric plexus of the sympathetic system which in men results in retrograde ejaculation, is usually from $0 \%$ to $10 \%$ when operating using the anterior retroperitoneal approach ${ }^{2,12-14}$. There is no anatomical reason for impotence to result from a standard ALIF procedure because the parasympathetic plexus responsible for erection is located deep in the pelvis ${ }^{7,11,14,29}$.

In an anatomical study Datta and Pai found that the lumbar sympathetic chain was located along the anterolateral aspect of the vertebral body. The psoas muscle was always posterior and considerably lateral to the sympathetic chain and ganglia were most well-formed, adjacent to the intervertebral discs ${ }^{30}$. The cadaveric study of Murata et al. found large variability, the number of ganglia ranged from 2 to 6 , the mean being 3.9. The mean lengths of rami connected to the $1^{\text {st }}$ and $5^{\text {th }}$ lumbar spinal nerves, respectively, were significantly longer and shorter than those connected to the $2^{\text {nd }}, 3^{\text {rd }}$, and $4^{\text {th }}$ nerves and were not distributed segmentally ${ }^{31}$. In another study of Feigl et al., the sympathetic chain entered the retroperitoneal space at the level of the vertebral body of L 2 in 70 of the 112 sides and showed the most consistent relationship to the medial margin of the psoas muscle at intervertebral disc level L2/3 (ref. ${ }^{32}$ ).

We found no post-SE neuralgia in our patients. However, even post-SE dysfunction described in our study leads to discomfort in some patients. The aim of minimally invasive surgeries is to avoid injury to all anatomical structures, including sympathetic chain because surgical $\mathrm{SE}$ is accompanied by several potentially disabling complications and we never advocate it. Some patients have no problems and others do not accept post-SE symptoms and to date, nobody has emphasized it. From this point of view, ALIF surgery at level L5/S1 is safe. In contrast, the anterolateral approach for ALIF at levels L4/5 and above the sympathetic chain lies in the middle of our access to the disc and it is necessary to separate and sometimes sacrifice it. At levels L4/5 and L3/4 we refer significantly less frequency of post-SE dysfunction after XLIF procedure because the sympathetic chain is located anteriorly to our access to the discs, but especially according to anatomical studies the lateral approach can cross the pathway of the sympathetic chain at levels L2/3 and L1/2 (ref. ${ }^{31}$ ).

Our study showed physical examination as visual evaluation and palpation of skin and neurological investigation were insufficiently reliable to disclose SE. Palpation of the skin did not reveal the difference in temperature of the legs even in difference up to $4.3^{\circ} \mathrm{C}$. Subjective symptoms of SE after spine surgery in our study were often false positive (patients had subjective difficulties without positive TG findings) and on the contrary, proved sympathectomy was often clinically false negative (TG had positive results, but patients had no subjective difficulties). The literature describes a number of possible uses for infrared TG testing but so far, only one publication has focused on objectively measuring SE effects that result from spinal surgery ${ }^{8}$. However, studies have described where therapeutic SE was performed, usually due to the symptoms of Raynaud's phenomenon, mostly upper chest. These studies included the thermogram results of infrared TG examination before and after SE. The thermograms showed a significant temperature increment in the hands following therapeutic surgery, corresponding to interruption of vasoconstrictive sympathetic activity to the vessels in the hands ${ }^{33,34}$. Similarly Gabrhelík et al. describe in their study of 24 patients, a temperature rise of at least $2{ }^{\circ} \mathrm{C}$ in the palms of $95 \%$ of the patients following the therapeutic upper thoracic SE ( ref. $\left.^{35}\right)$. TG serves as useful and sensitive test for the diagnosis of sympathetically maintained pain and can detect sympathetic dysfunction even in the absence of clinical findings ${ }^{36}$. Some authors performed TG in patients with hyperhidrosis to control an effectiveness of SE (ref. ${ }^{22,34,37}$ ). Rieger et al. studied the skin on the feet and showed a clear average temperature increase of $2.8{ }^{\circ} \mathrm{C}$ (range $2.3-4.2{ }^{\circ} \mathrm{C}$ ) after SE on the one side, compared with the unoperated side ${ }^{22}$. According to Vardasca et al., who examined 39 healthy subjects for temperature difference in symmetrical parts of the body, the highest measured difference in the synoptic images was $0.4{ }^{\circ} \mathrm{C} \pm 0.3{ }^{\circ} \mathrm{C}$ on the regional images ${ }^{38}$. In our control group of patients after posterior disc herniation surgery, the difference in temperature was up to $0.9{ }^{\circ} \mathrm{C}$. Thus, positive results of TG as a proof of SE, was chosen minimally $1.0^{\circ} \mathrm{C}$.

For the purpose of the actual examination of patients in our study, a FLIR thermal imaging camera was used, which can calculate the temperature of objects with a temperature range of $-20{ }^{\circ} \mathrm{C}$ to $+120{ }^{\circ} \mathrm{C}$, with adjustable emissivity values, relative humidity and ambient temperature and reflective temperature values. The use of infrared TG in medicine is experiencing a renaissance, especially due to the availability of more sensitive TG cameras. The indisputable advantage of this method is its non-invasiveness and safety, which means the examination is very comfortable for the patient. Due to the range of factors that can affect the results, emphasis is placed on standardization of the examination. The Glamorgan Protocol, strictly 
applied for image recording and evaluation, increases the reproducibility of findings from thermal images. Any other body position for image recording is possible but the degree of reproducibility is decreased ${ }^{15-17}$. In our study, however, the requirement for standard conditions was not as strict as we did not consider the temperature of the whole body, which of course may change due to changes in ambient conditions. Instead, we compared two identical points on symmetrical parts of the human body. The only problem in the diagnosis of SE effect could thus be a false positive result when an increased temperature in the thermogram is caused by another factor such as an inflammatory focus. However, with carefully recorded history and clinical examination, we minimized this factor.

\section{CONCLUSION}

Sympathectomy was diagnosed in $0.5 \%$ after ALIF at L5/S1, in $15 \%$ after ALIF at Th12-L5 and in 4\% after XLIF at T12-L5.

Sympathectomy seriously reduced the quality of life only in two cases but before surgery we can never foresee this. This is why we avoid injury to the sympathetic chain.

Physical examination as visual evaluation and palpation of skin and neurological investigation were insufficiently reliable for disclosing sympathectomy.

Subjective symptoms of sympathectomy were often false positive and proven sympathectomy by TG was often a clinically false negative.

The advantage of thermography for the confirmation of sympathectomy is its non-invasiveness, safety and patient comfort.

\section{ACKNOWLEDGEMENT}

Author contributions: LH, JS, MA: literature search; LH, JS: manuscript writing; LH, JS, MA: study design; LH, JS: data collection and analysis; LH, JS, MA: data interpretation; LH, JS: statistical analysis, figures; LH: final approval.

Conflict of interest statement: None declared.

\section{REFERENCES}

1. Crock HV. Anterior lumbar interbody fusion: indications for its use and notes on surgical technique. Clin Orthop 1982;165:157-63.

2. Zdeblick TA, David SM. A prospective comparison of surgical approach for anterior L4-L5 fusion. Spine 2000;25:2682-7.

3. Bergey DL, Villavicencio AT, Goldstein T, Regan JJ. Endoscopic lateral transpsoas approach to the lumbar spine.Spine 2004;29:1681-8.

4. Ozgur BM, Aryan HE, Pimenta L, Tailor WR. Extreme lateral interbody fusion (XLIF): a surgical technique for anterior lumbar interbody fusion.Spine J 2006;6:435-43.

5. Pimenta L. Lateral endoscopic transpsoas retroperitoneal approach for lumbar spine surgery. Paper presentation at the VIII. Brazilian Spine Society Meeting 2001. Belo Horizonte, Minas Gerais, Brazil.

6. Kang BU, Choi WC, Lee SH, Jeon SH, Park JD, Maeng DH, Choi YG. An analysis of general surgery-related complications in a series of 412 minilaparotomic anterior lumbosacral procedures. J Neurosurg Spine 2009;10(1):60-5
7. Rajaraman V, Vingan R, Roth P, Heary RF, Conklin L, Jacobs GB. Visceral and vascular complications resulting from anterior lumbar interbody fusion. J Neurosurg (Spine 1) 1999;91:60-4.

8. Schulte TL, Adolphs B, Oberdiek D, Osada N, Liljenqvist U, Filler TJ, Marziniak M, Bullmann V. Approach-related lesions of the sympathetic chain in anterior correction and instrumentation of idiopathic scoliosis. Eur Spine J 2010;19:1558-68.

9. Kramis RC, Roberts WJ, Gillette RG. Post-sympathectomy neuralgia: hypotheses on peripheral and central neuronal mechanisms. Pain 1996;64(1):1-9.

10. Carragee EJ, Mitsunaga KA, Hurwitz EL, Scuderi GJ. Retrograde ejaculation after anterior lumbar interbody fusion using rhBMP-2: a cohort controlled study. Spine J 2011;11:511-6.

11. Faciszewski T, Winter RB, Lonstein JE, Denis F, Johnson L. The surgical and medical perioperative complications of anterior spinal fusion surgery in the thoracic and lumbar spine in adults. Spine 1995:20:1592-9.

12. Hrabálek L, Adamus M, Wanek T, Macháč J, Tuček P. Surgical complications of the anterior approach to the L5/S1 intervertebral disc. Biomedical Papers 2012;156(4):354-8.

13. Saraph V, Lerch C, Walochnik N, Bach CM, Krismer M, Wimmer C. Comparison of conventional versus minimally invasive extraperitoneal approach for anterior lumbar interbody fusion. Eur Spine J 2004;13:425-31.

14. Tiusanen H, Seitsalo S, Osterman K, Soini J. Anterior interbody lumbar fusion in severe low back pain. Clin Orthop Relat Res 1996;324:153-63.

15. Ammer K. The Glamorgan Protocol for recording and evaluation of thermal images of the human body. Thermology International 2008;18:125-44.

16. Ammer K. Standard Procedures for Infrared Imaging in Medicine 10/2012; ISBN: 978-1-4398-7249-9 In: Medical Infrared Imaging. Principles and Practice, Chapter: 32, Publisher: CRC Press, Taylor \& Francis Group, pp.32.1-32.14.

17. Ammer K. Need for Standardisation of Measurements in Thermal Imaging In: Wiecek B (ed) Thermography and Lasers in Medicine. Akademickie Centrum Graficzno-Marketigowe Lodart S.A, Lodz 2003, pp. 13-18.

18. Uematsu S, Jankel WR, Edwin DH, Kim W, Kozikowski J, Rosenbaum A, Long DM. Quantification of thermal asymmetry. Part 2: application in low-back pain and sciatica. J Neurosurg 1988;69(4):556-61.

19. Furlan AD, Mailis A, Papagapiou M. Are we paying a high price for surgical sympathectomy? A systematic literature review of late complications. J Pain 2000;1:245-57.

20. Merskey H, Bogduk N. Classification of Chronic Pain: Descriptions of Chronic Pain Syndrome and definition of Pain Terms. $2^{\text {nd }}$ ed. Seattle: IASP Press. 1994

21. Mizuno S, Takebayashi T, Kirita T, Tanimoto K, Tohse N, Yamashita T. The effects of the sympathetic nerves on lumbar radicular pain. J Bone Joint Surg (Br) 2007;89-B:1666-72.

22. Rieger R, Pedevilla $S$. Retroperitoneoscopic lumbar sympathectomy for the treatment of plantar hyperhidrosis: technique and preliminary findings. Surg Endosc 2007;21:129-35.

23. Buche M, Randour P, Mayne A, Joucken K, Schoevaerdts JC. Neuralgia following lumbar sympathectomy. AnnVasc Surg 1988;2:279-81.

24. Raskin NH, Levinson SA, Hoffmann PM, Pickett JBE, Fields HL. Postsympathectomy neuralgia: amelioration with Diphenylhydantoin and Carbamazepine. Am J Surg 1974;128:75-8.

25. Rieger R, Laureiro MP, Pedevilla S, Oliveira RA. Endoscopic lumbar sympathectomy following thoracic sympathectomy in patients with palmoplantar hyperhidrosis. World J Surg 2011;35:49-53.

26. Mockus MB, Rutherford RB, Rosales C, Pearce WH. Sympathectomy for causalgia. Patient selection and long-term results. Arch Surg 1987; 122:668-72.

27. Lacroix H, Vander Velpen G, Penninckx F, Nevelsteen A, Suy R. Technique and early results of videoscopic lumbar sympathectomy. Acta Chir Belg 1996;96:11-4.

28. Bossut DF, Shea VK, Perl ER. Sympathectomy induces adrenergic excitability of cutaneous C-fiber nociceptors. J Neurophysiol 1996;75:514-7.

29. Mayer HM, Wiechert K. Microsurgical anterior approaches to the lumbar spine for interbody fusion and total disc replacement. Neurosurgery 2002;51(Suppl 5):S159-65.

30. Datta S, Pai U. Paradiscal extraforaminal technique for lumbar 
sympathetic block: report of a proposed new technique utilizing a cadaver study. Pain Physician 2004;7:53-7.

31. Murata $Y$, Takahashi K, Yamagata M, Takahashi Y, Shimada Y, Moriya $\mathrm{H}$. Variations in the number and position of human lumbar sympathetic ganglia and rami communicantes. Clin Anat 2003;16:108-13.

32. Feigl GC, Kastner M, Ulz H, Breschan C, Dreu M, Likar R. Topography of the lumbar sympathetic trunk in normal lumbar spines and spines with spondylophytes. British Journal of Anaesthesia 2011;106:260-5.

33. Murata K, Omokawa S, Kobata Y, Tanaka Y, Yajima H, Tamai S. Longterm follow-up of periarterial sympathectomy for chronic digital ischaemia. J Hand Surg Eur Vol October 2012; 37:788-93.

34. Tsai JC, Lim KB, Lin SY, Kao MC. Thermographic study of palmar and facial skin temperature of hyperhidrosis in patients before and after thoracic sympathectomy. J Formos Med Assoc 2000;99:466-71.
35. Gabrhelík T, Michálek P, Pieran M, Adamus M, Berta E, Dobešová J, Marková K. Efektivita radiofrekvenční horní hrudní sympatektomie v léčbě Raynaudova fenoménu kontrolovaná termografií - pilotní studie. Bolest 2007:10(2):95-100.

36. Friedman MS. The use of thermography in sympathetically maintained pain. lowa Orthop J 1994;14:141-7.

37. Chuang TY, Yen YS, Chiu JW, Chan RC, Chiang SC, Hsiao MP, Lee LS Intraoperative monitoring of skin temperature changes of hands before, during and after endoscopic thoracic sympathectomy: using infrared thermograph and thermometer for measurement. Arch Phys Med Rehabil 1997;78:85-8.

38. Vardasca R, Ring E F J, Plassmann P, Jones C D. Thermal symmetry of the upper and lower extermities in healthy subjects. Thermology International 2012; 22(2-22):53-60. 